\title{
Norbert Elias and the Lost Young Worker Project.
}

John Goodwin and Henrietta O'Connor

Centre for Labour Market Studies,

University of Leicester.

\begin{abstract}
Forty years ago, between 1962-1964, fieldwork was carried out on the research project Adjustment of Young Workers to Work Situations and Adult Roles. Using archived materials relating to the little known Norbert Elias project, this paper has two aims. First, to introduce this largely unknown aspect of Elias's work to a wider audience. Second, to explore in detail Elias's contributions to the project by piecing together his ideas and hypotheses from archived materials. During the early stages of the research, Elias suggested that the transition from school to work constituted a 'shock' experience and that young people would experience initial difficulties in adjusting to their new role. He suggested that difficulties would emerge in their relationships with older workers, with family and with their new income. For the first time this paper presents Elias's 'shock' hypothesis, and his thoughts on school to work transitions. The paper concludes by reflecting on the value of the shock hypothesis and the possible impact that the Adjustment of Young Workers to Work Situations and Adult Roles project may have on Elias standing in British sociology.
\end{abstract}


Introduction

In the early 1960s Elias also successfully applied for a major research grant...to investigate school leavers' adjustment to working life. The results of this 'Young Worker Project' eventually appeared in publications by colleagues at Leicester, not by Elias himself (Mennell 1992: 21-22).

Forty years ago, in 1962, fieldwork began on the research project 'Adjustment of Young Workers to Work Situations and Adult Roles' (commonly know as the Young Worker Project). Led by Norbert Elias, this was an interview-based survey of the school to work transition experiences of nearly nine hundred young adults in Leicester, UK. The Department for Scientific and Industrial Research awarded the project $£ 15,081$ for three years beginning in April 1962. The research was based on Elias's assertion that the transition from school to work constituted a 'shock' experience and that young people would experience real difficulties in adjusting to their new role as adults and workers. Suggesting that much of the early research on young people was essentially 'adult centred' and based on the experiences and perspectives of adults rather than the young people themselves, Elias argued that his approach would be radically different from other studies of the time as 'adult investigators are apt to investigate either their own problems with regard to young people...not problems which confront, and which are experienced by the young generation itself' (Elias 1962a: 1). Instead Elias wrote that this project would be

...concerned with the problems which young male and female workers encounter during their adjustment to their work situation and their entry into the world of adults. When they go to work, or begin to train for work, young workers have to make a wider adjustment to a situation and to roles which are new to them, whose implications are often imperfectly understood by them and by the adults concerned, and for which they are in many cases not too well prepared. (Young Worker Project, 1962b: 2)

This broad position was then translated into five specific areas of enquiry adjustment to relationships with older workers and supervisors; adjustment to job problems; adjustment to role as workers; adjustment to role as 'money-earner' in home relations; and adjustment to role as 'money-earner' in leisure time. Initially the idea was for the data to be collected via interviews, informal discussions, case studies and participant observation, however only interviews were used. The interview schedule was semi-structured with a mixture of open and closed questions. The schedule contained 82 questions organised in five sections - Work, Family and Expenditure, Leisure, School and Work, and General. The interviewers were asked to write all answers to questions verbatim if possible and always in as full detail as the 
time and circumstances allowed. The sample of young adults was drawn from the Youth Employment Office index of all Leicester school leavers from the summer and Christmas of 1960 and the summer and Christmas of 1962. At the end of the fieldwork in 1964, 882 interviews, plus a pilot survey of 28 interviews had been completed.

However, at the start of the research in 1962, the researchers involved with the project were unaware that Elias had arranged to take up a Chair in Sociology at the University of Ghana from the October of that year. Although Elias attempted to direct the project remotely via a research committee, problems with working practice emerged, the Research Officers ${ }^{[1]}$ on the project resigned and other members of staff distanced themselves from the research. The project then became characterised by acrimony, distrust and feelings of failure, and entered the 'Leicester air' as something never to be referred to again. With the exceptions of Keil et al (1963b), Ashton (1973, 1974) and Ashton and Field (1976) in which a sample of the cases and background literature were used, and despite being one of the largest government sponsored projects on young workers of the time, the data from this project has remained unanalysed and unexplored for forty years.

In 2000 nearly nine hundred of the original interview schedules and some background materials were recovered from where they were archived in the mid 1970s. Using this material and other archive documents, it is possible, for the first time, to examine Elias's thoughts on school to work transitions and explore his 'shock' hypothesis in more detail. As such, the remainder of the paper will be structured as follows. First, the possible reasons as to why this Elias project has remained unexplored are considered. The discussion then moves on to a consideration of Elias's shock hypothesis. This will be done by using his writings, minutes of meetings and correspondence relating to the Young Worker Project. In order to explore and understand Elias's approach and ideas on shock, the intention is to set this discussion in the context of some of his other writings.

\section{Ignored or Lost? Elias and Youth Transitions to Work Situations}

Elias's work has been considered in detail (Mennell 1992; Hughes 1998; Van Krieken 1998; Smith 2000) and there have been those who have taken Elias's ideas and applied them to a broad range of concerns and areas of enquiry (Dunning 1981, 1999; Van Krieken 1989, 1999; Hughes 1997; Fletcher 1997; Tabboni 2001). The broad range of applications of Elias's work reflects Elias's own concern to explore the breadth of social phenomenon in order to demonstrate that a long term, dynamic (rather than static) framework offers a better understanding and leads to a more 
adequate enquiry. According to authors such as Mennell (1992) and Van Krieken (1998) (and even Elias (1970) himself) Elias was unique, given the increasing division of labour amongst sociologists, in that he wrote across so many substantive areas and the value of his work is its interconnectedness (Mennell 1992: 279-280). As such Elias's interest in youth transitions to work and adulthood is not surprising. What is surprising, however, is that no one has engaged directly with, or explored fully, Elias's interest in youth transitions or his foray into the arena of large-scale government funded research in this area. This despite Szakolczai's (2000) assertion that the main aspects of Elias's life and work are well researched and well known. The Young Worker Project has received scant attention within the existing literature on Elias and remains largely unknown outside the University of Leicester or beyond those fully familiar with every aspect of Elias's life and work. Indeed most introductions to Elias do not mention this research at all (see Fletcher 1997; Van Krieken 1998; Hughes 1998; Korte 2001) nor does Elias mention the project in his autobiographical writings (Elias 1994). The exception to this is Mennell (1992) in which the young worker project receives the very briefest of mentions. Whilst this is a tantalising reference, Mennell (1992) does not explore the reasons why Elias did not publish the findings himself nor does Mennell provide any additional detail on this 'major' research grant obtained by Elias.

One possible reason why this project may have received little attention in the Elias literature is that it may have been perceived by later scholars as a 'Departmental' project and not really part of Elias's body of work. Indeed, Elias referred to the project as a 'Departmental' project and the early minutes of meetings identify it as such. Likewise the management and 'staffing' of the project in the early phases of research involved a number of members of the Sociology Department at Leicester including Ilya Neustadt, Sheila Williams (now Allen), Percy Cohen, Richard Brown and Anthony Giddens. However, there are a number of problems with this view. In the correspondence from DSIR Elias is clearly identified as the primary grant holder (see letter from Albert Cherns to Elias 12 November 1965). From the surviving background documents it is clear that Elias was fully involved in the development of the proposal, wrote a number of memoranda on the aims and focus of the project and commented on the design of the research instrument. Elias insisted that his view and his approach to the research be adhered to otherwise he would resign from the research project (Elias 1963). Elias was involved in the appointment of the original research team and the appointment of those who were later appointed to try and revive the project. Elias attended numerous meetings on the project before he left for the University of Ghana, and during his vacations from Ghana. Whilst in Ghana, Elias corresponded regularly about the research with Neustadt, and the other members 
of the team. In Neustadt's correspondence with Elias regarding the project, Neustadt sought and always deferred to Elias's views in relation to the research despite the fact that Neustadt was the Head of Department at the time (see Neustadt 1964a). In the final stages of the research it was to Elias that the original research team wrote, explaining their reasons for resigning from the project. Finally, Elias expressed, and eventually got, his wish to return to Leicester as a Senior Research Fellow and to supervise the Young Worker Project (see Neustadt 1964a). The archived material clearly indicates that Elias maintained his interest in young people's adjustment to work from the early 1960s to the mid 1970s and hoped that something would eventually happen to the data collected from the Young Worker project over a decade earlier.

However, an additional reason that may have discouraged a fuller discussion of this project is the problematic and difficult circumstances that surrounded the end of the data collection in 1964. As Brown (1987) suggests

Someone who had thought so long and to such good effect about sociological problems as he had could find it difficult to understand why others did not see things as he did, or to take on board ideas and points of view different from his own. There was in my experience one major disagreement about the conduct of a research project which proved quite damaging to all concerned and to the progress of the research (Brown, 1987: 538).

Some of the problems surrounding this project, and the reasons for the resignation of the original Research Officers have been reflected on elsewhere but have never been published ${ }^{[2]}$. Beyond Elias's remoteness in Ghana and the acknowledged difficulties in communication ${ }^{[3]}$, there were three main areas of disagreement between Elias and the research team, including an ongoing argument over the researchers' rights to publish. Despite the Research Officers' eagerness to publish the results from the research, the research team felt that Elias had vetoed the publication of an article they had written. Elias (and Ilya Neustadt) instructed that there should be no publications or interim reports based on the data. The following exchanges took place towards the end of the fieldwork:

We are very disappointed that you, and Ilya, intend to concentrate on preparing a final report rather that to publish, in addition, interim articles on specific aspects which would not be fully dealt with in the one report...We feel that unless it is the policy that we are free to submit such articles for publication after constructive criticism, the situation is unacceptable. (Keil and Riddell 1964: 1)

My dear Teresa and David, you seem to think that I am a jealous man who wants to prevent you from publishing anything independently of 
me. I assure you nothing can be further from my mind...If you care to take up some specific part issue of the Young Worker Project and publish an article on it under your own name I have not the slightest objection. But is quite a different matter if you wish to publish an interim report on the whole project...If you are concerned for your future career, realistically speaking, I think nothing could be better for you than a really impressive final report on the Young Worker Project in which, you need not doubt, all due credit will be given for what you have done. (Elias 1964a: 1-2)

A second area for disagreement, and perhaps the main area of complication, was an ongoing debate between Elias and the Research Officers as to the nature of the theoretical framework and the composition of the sample. From the outset of the research, Elias was keen to capture the initial experiences of young people entering the workplace as he felt that the young people's experience prior to work would not prepare then for what was to come. However, according to Elias, the Researcher Officers had interpreted the early discussions to mean that this research was to be a study of 'work' per se. They identified their problem as

...given such a number of young people from known schools, home backgrounds, and work situations, what is their experience when they become workers ?...[We] do not think we should be content with knowing that they have difficulties and to what extent...but wish to distinguish certain factors which make for certain types of experience in the work situation. (Keil et al 1963a: 2)

Elias argued that the study should not be about work but instead the 'work situation' as many of the problems faced by young people rarely sprang from work in isolation of other situations. For Elias this came much closer to offering a better understanding of the problems faced by young workers than could be offered by a study of 'work'. As for the research problem of the Research Officers, Elias suggested that their approach was simply trying to look for causal relationships between the different aspects of the sample. Elias felt that such an approach was far too conventional and ignored the relationships and processes that surround the work situation that constitute the young workers experience. In response to their initial theoretical problem, Elias suggested that their working hypothesis

...is even worse. It is based on the idea...that men's [sic] attitudes and behaviour are the passive effects of a social environment here represented by A, B and C. It has been by now fairly widely accepted that this type of billiard ball causality: Billiard ball B (behaviour and attitudes) in its course determined by the movement of Billiard ball A (Features of the background...features of the work situation, labour market), does not provide a very suitable model of thinking in relation to what one actually observes. I would suggest that the Research 
Officers think of the experiences of the young workers...[and] that they cease to think in wishy-washy terms like 'Background' or 'Features of the Background' and learn to think in situations as wholes, in configurations...(Elias, 1963: 7)

According to Elias (1963), the differences in the understanding of his ideas and concepts, contained within the original grant application, meant that the researchers were undertaking a different project to that originally proposed by him. The ongoing misunderstandings over research direction, and Elias's constant suggestion that the researchers lacked even a basic understanding of what the research was about, led the researchers to perceive that Elias had no real confidence in them or their ability.

There were similar differences of opinion about the composition of the sample. Discussions as to the exact composition of the sample took place throughout 1962 and culminated with the agreement that the investigation would be restricted to all those working in Leicester who had worked for less than one year. It was also agreed that the sample would be further stratified into four occupational categories or skill levels - unskilled, semi-skilled, skilled and clerical. However, it was as suggested by the Research Officers and Brown et al (1963) that limiting the sample to those who had less than one years experience of work would reduce the possibility of exploring the shock hypothesis that Elias intended. They argued that the younger members of the sample had hardly had time to get over the excitement at not having to adhere to the rigid discipline of school and earning money to experience the 'shock' that Elias refers to (Brown et al 1963). Keil and Riddell (1963a) also expressed their concerns that the sample should not be stratified in terms of skill level as they had doubts as to how accurately the Youth Employment Service had recorded this information.

A third area for disagreement related to boarder methodological debates and stem from the coming together of two very different traditions. The two research officers Keil and Riddell came from the British tradition of empirical sociology with its emphasis on survey research and were recruited having previously worked on other large-scale quantitative research projects elsewhere. Teresa Keil came from the University of Liverpool having worked with Joseph Banks on a study exploring the impact of technological change and David Riddell came from the Scottish Social Survey based at the University of St Andrews. Bryan Green, one of the research assistants was also experienced in market research interviewing. Elias came from a sociological tradition that was profoundly at odds with the abstract empiricism that was characteristic of social scientific research in Britain and America at that time. 
The approach of the two different traditions can be contrasted very clearly. For example, in the early 1970s Elias was interviewed about the Young Worker project by Jennifer Platt for her book Realities of Social Research $(1976)^{[4]}$. In the interview Elias suggested that through the Young Worker Project he hoped to be able to demonstrate that statistical enquiry could also be undertaken within a dynamic framework and that it is only when the data is generated and analysed that the shortcomings of the survey can be seen. Based on these shortcoming one then can undertake a revised and improved investigation. Elias also suggested that he felt that the researchers did not believe his assertions that it was possible to develop a precise and straightforward questionnaire that could also access or get at the 'experiential side' and explore the young workers experiences. Elias desire to use the data generated form the survey to identify further studies was translated to the research officers as the need to undertake additional 'case studies'. However, the research officers received the apparent need for case studies very critically. As Keil (1964) suggests

...every meeting with you has ended in your saying that we cannot understand your ideas, that we are too concerned with numbers and statistics, too pedestrian, too inhibited by our training. I have thought a great deal about the source of such lack of mutual understanding and it seems to me to lie in a fundamental disagreement about the scope and limits of large-scale research which ahs resulted in such turmoil and acrimony over the Young Worker project. (Keil 1964: 1)

Keil (1964) goes on to suggest that she felt the Young Worker project was a real opportunity to undertake a large survey that would provide systematic information about the experiences of young people entering work for the first time. For Keil the value of the data resides within the fact that the survey was based on a large, properly constructed sample and a questionnaire designed to obtain factual information. She goes on

Why else is there a need to interview $1,000+$ young people if one is only concerned, in fact, with the experiences of 20 or 30 young people who are somehow 'significant'?... For me a large-scale survey is not a simple multiplication of a small one, but an opportunity to test certain hypotheses which cannot be tackled otherwise. (Keil 1964: 1) 
For Elias the value of the study did not ultimately reside in the ability to produce statistically significant quantitative results in the ability to explore the transition to work as the young people experienced and accounted for it themselves.

Whatever the reasons for the obscurity of this major area of research within the body of work by, or about Elias, it is clear that Elias was sufficiently involved with the project and his ideas determined the direction of the research to warrant a fuller exposition.

\section{Elias and the 'Shock Hypothesis'}

As suggested above Elias's contributions to the Young Worker Project have received scant attention, and as such, the only really full source of documentary evidence on the project is in the archived collection of Elias papers at the Deutsches Literaturarchiv, Marbach, Germany. Additionally, some of the original research team had retained copies of their young worker documents including minutes of meetings, correspondence with Elias and memoranda. Together, papers from the archive and from the original research team provide some insight into the project and highlight much of Elias's 'transition as shock' hypothesis. However, using material from sources such as this does have potential problems. For example, there are obvious difficulties in the piecing together of different aspects of an approach from such secondary sources and this could lead to an imperfect understanding. Likewise problems emerge in that one did not observe first hand the interactions or discussions that took place regarding Elias's original approach. As such it is difficult to see the full genesis of the ideas or how they were shaped via the discussion that took place. Questions must also be raised about the extent to which these documents accurately record the discussions that took place and about selectivity in terms of what archive material was retained and what was discarded.

Yet despite these concerns, piecing together Elias's original thoughts on this research and his shock hypothesis remains a worthy task as it adds a further dimension to Elias's own writings and illustrates some of the themes Elias dealt with elsewhere in his work. In doing so the use of the archive materials outlined above is inevitable as this is all that survives in terms of the project. Remarkably, the archive documents do indicate a consistency in Elias's thoughts regardless of whether they are recorded in minutes, correspondence or memoranda and from these archive materials it is clear that Elias identified eight specific problems to the experience of transition as a one of shock. They were 
- The prolonged separation of young people from adults;

- The indirect knowledge of the adult world;

- The lack of communication between adults and children;

- The social life of children in the midst of an adult world with limited communication between the two;

- The role of fantasy elements in the social and personal life of the young vis-à-vis the reality of adult life;

- The social role of young people is ill-defined and ambiguous;

- Striving for independence through earning money constitutes a new social dependence (on work rather than parents)

- The prolonging of social childhood beyond biological maturity.

Although each of these issues is interesting it would be impossible here to provide a full exposition of each factor. As such, in the discussion that follows, we have given particular attention to the role of indirect knowledge of the adult world and role fantasy versus the reality of adult life in the shock experience.

The Civilising of Children: The Separation from Adults and the Role of Fantasy

... I want to say that "culture shock' is in my view a very inappropriate term for what we are getting at. It runs smoothly from the lips, that is quite true, it sounds nice. But we are not trying to find out about a shock which "culture" gives to people. It is the work, the occupation, the whole undreamed of reality of the adult world which is responsible for the stresses of adolescents in that situation...I have always preferred the term "shock-experience", to the term "shock". The most precise expression of which I can think at the moment is probably "reality shock". That is, in fact, what it is likely to be. (Elias 1962, p.1)

Given the interrelationship between sociogenesis and psychogenesis, Elias argued that the socialisation of children cannot take place behind closed doors and the learning of adult behaviours is only possibly due to the presence of others. In 1980, Elias reflected on the socialisation of children and the changing relationship between children and their parents in his lecture The Civilizing of Parents (Elias 1980; Goudsblom and Mennell 1998). In this work Elias suggested that child from early in life, and through adolescence, is subject to an individual civilising process that shapes their behaviour, and in turn emerge high degrees of self-restraint and foresight in line with the prevalent standards of behaviour at that time. As Van Krieken (1998) argues, 
for Elias childhood is the 'main 'transmission belt' for the development of the habitus' (Van Krieken 1998; 156) of a given society

Human social life in the form of urban-industrial nation-states encloses each individual person in a complex network of longer more differentiated chains of interdependence. In order to claim to be an adult...in order to fulfil an adults functions... it is necessary to have a very high degree of foresight, restraint of momentary impulses, for the sake of long-term goals and gratifications...it requires a high degree of self-regulating restraint of drives and affects (Elias 1980: 201-202)

Children have to learn the self-control of drives and affects through the course of relations with other people and 'according to the pattern and extent of socially given drive and affect regulation' (Elias 1980: 202). The more complex a society the more complex this process of transition to adulthood or the learning of adult norms becomes. According to Elias, the more complex a society, the more differentiated the social functions are and the more interdependent people become. In such a society, to fulfil the social functions, more foresight is required in order to subordinate 'momentary inclinations to the overriding necessities of interdependence' (Elias 2000: 380; Mennell 1992: 96). For example, if one takes the social function of work, in a complex industrial society such as ours, the structure of drives and affects required for this adult behaviour is further from the behaviour of children than that required in simpler societies. To illustrate this Elias (1980) suggests that in Eskimo society there is a direct developmental line between children's play behaviour (playing with bows and arrows or learning to treat skins) and adult behaviour's of hunting, tent making and survival (Elias 1980: 202). The child's or young person's behaviour corresponds to a high degree with adult reality whereas in complex industrial societies it does not. As such, in a simpler society, Elias (1980) argues the individual civilising transformation is temporally shorter and less deep-rooted (Elias 1980: 202).

A dimension of adult behaviour that children had to learn through their transition to adulthood was the difference between fantasy and reality. Like other aspects of knowledge and behaviour, the difference between fantasy and reality depends on prevalent standards at that time (i.e. it varies historically and between societies). For example, Mennell (1992) suggests that in industrial complex societies there is a very clear division between fantasy and reality and people have to behave accordingly, if they act out their dreams in a way that conflicts with prevalent standards their sanity will be questioned (Mennell 1992: 162). In the Young Worker Project Elias wanted to examine how young people experiencing the transition from school to work and 
acquired and adjusted to the prevalent adult standards or norms of behaviour. Elias (1961) suggested that for young people

...their entry into work places young workers into a different position not only in relation to parents or to friends, but in relation to adults who are strangers - adult workers, supervisors, managers etc on whom they depend...The norms, the behaviour and attitudes of the adults with which they now come into contact often differ considerably from those with which they are familiar in their own family circle or from their contact with masters at school.(Elias 1961: 1)

For Elias, the norms, and attitudes or new codes of behaviour exhibited by the adults in the workplace involved problems of competition and co-operation, conforming and non-conforming in factories and workshops and coping with tensions in social relations (Elias, 1961: 1). The transition process and the adjustment to working life via the learning of adult norms, for Elias, was not a simple process. The difficulty arose in that the norms, the behaviour and attitudes of adults in the workplace differed considerably to those adults the young people were familiar with. In these 'already known' relationships the position of the young person is clearer as a subordinate to the adult figure. For example a child is subordinate to their parents and a 'teenager' is in a subordinate role to their teacher. Through the processes of sociogenesis and psychogenesis over time a power ratio has emerged in these relationships, which supports the young person's subordination. In turn the young person displays appropriate behaviour. However, in our current society, when the young person begins to make the transition to work and adulthood their role becomes less clear. This, he argues, is due to the limited amount of contact between young people and adults over and above family, friends and teachers. For example, at a meeting of the young worker project team it was argued that

The central problem arises from the fact that a complex society such as ours requires customarily a prolonged period of indirect preparation and training for adult life. By indirect I mean from the age of 5 to 14,15 or 16, the growing up children of our society are trained for their adult tasks in special institutions which we call schools, where they learn, where they acquire the knowledge about the adult world past, present and future not by direct contact with it, but largely from books. Their actual knowledge of the adult world, their only contacts with adults, are relatively limited. (Young Worker Project, 1962a: 2)

Elias suggested that this is radically different from the children growing up in 'simpler' European societies of previous periods in which children and young people had more direct contact with adults. In our current society problems or difficulties can arise in the adjustment to adult and work roles as the young workers are now neither fully adult nor fully children and they experience contact with different adults and 
different norms of adult behaviour. As such, Elias suggested that this research begin with the hypothesis that

...nothing, or very little, that the school leaver has been taught has prepared him or her for the experience of starting work; that the experience was a "shock" experience. (Young Worker Project, 1962b: 2)

Elias's notion of shock is reinforced with comments made at the fifth meeting of young worker project team. Here Elias quoted an example of the shock experienced by a young worker at being told not to work too hard. The minutes suggest that Elias argued that the problem could be approached without first needing to find out the adult norm of not working too hard, instead the emphasis should be on "what the young workers are faced with, as they see it and describe it in talking about their first few weeks in the factory' (Young Worker Project, 1962b: 2). Elias wanted to understand how the young people experienced the norm of not working too hard. For example, it could be argued that shock emerges in that the young adults have moved from a situation where adults, in the form of teachers at school, have instructed the young adults to work hard and have administered punishments to those who did not, to a situation where unfamiliar adults are instructing, advising and encouraging the young people to behave in a way that was previously discouraged. The existence of the young worker is threatened by the fact that their social world changes and they come into contact with behaviours and norms that are totally unfamiliar to them. To further illustrate this idea, in meetings and in various memoranda, Elias reflects on the role of money in the transition process. For Elias, one of the main areas of transition to work that required the young worker to learn new behaviours and norms was in the acquisition and management of money. The process of having one's own money and having to work in exchange for this money, represented for Elias a further change in the social reality of the young worker. He suggested that the young people made the transition from a

...situation in which money, and food and clothing are given, and received as a right, without anything being given by the child in exchange, to a situation in which money is only given in exchange for work by the receiver. (Young Worker Project, 1962c: 1)

These changes to the social reality of the young worker, experienced as part of the transition from school to work, according to Elias caused anxiety or shock. These assertions by Elias build on points made in The Civilising Process.

Any other behaviour, any breach of the prohibitions or restraints prevailing in their society means danger...And the peculiarly emotional undertone so often associated with moral demands...reflects 
the danger in which any breach of the prohibitions places the unstable balance of all those for whom the standard behaviour of society has become more or less 'second nature'. These attitudes are symptoms of the anxiety aroused in adults when the structure of their own drives, and with it their own social existence and the social order in which it is anchored is even remotely threatened. (Elias 2000: 141).

Elias argued that the transition from childhood to adulthood, from school to work is one of the great anxiety arousing transitions as the young person's social existence and social order are threatened. In previous societies, according to Elias, ceremonies or 'rites of passage' grew up around the transitions between social roles to help ease the anxiety. Indeed, Elias suggests that all situations, which were liable to arouse fear or anxiety, such as the transition from one socio-biological state to another, were marked by public ceremonies as means of helping the individual contain their fears and anxieties. However Elias suggests that the communal ceremonies of passage formerly attached to the transition from childhood to adulthood have completely lapsed' (Elias 1962a: 2).

For Elias, a further contributing factor to the 'shock experience', part of the transition from school to work and adulthood, was the degree of difference between fantasy and reality held by the child versus the reality of the adult world. Indeed Elias (1962) suggests

Somehow the experience of many youngsters when they grow up in our society seem to me similar. They perceive more the wider choices of adulthood than its restraints and frustrations. (Elias 1962, p.2)

As part of acquiring the prevalent adult standards or norms of behaviour in the work place, the young workers had to also learn the prevalent standards in the differences between fantasy and reality at that time. For Elias, the gap between childhood and adolescent dreams and their adult reality is great and, given the absence of relationships between children and other adults (and the adult world), Elias suggested that children have developed fantasies about their future adult role. Children have to develop fantasies about their future adult role as they have not experienced it nor do they have much contact (before they enter work) with adults who have. Elias (1962) goes on

Before they enter their job, adolescents have a highly selective and still rather unrealistic perception of the adult world and of their life in it. The encounter with reality enforces a reorganisation of their perception. This is a painful process for at least two different reasons. First, because every strongly enforced reorganisation of perceptions is painful. Second, to all intents and purposes the "social reality" to which the youngsters have to get used, is unsatisfactory and the gap 
between the adult reality as it turns out to be is very great indeed. This is the objective situation...We are after the actual experiences to which it gives rise..."shock-experience" or "reality-shock" understood as something which may have a variety of forms, which may sometimes be sudden and biting and sometimes slowly coming over the years ending in a final shock of recognition that there will never be anything else but that, seems to me our best bet. (Elias 1962, p.1)

For Elias, given the absence of relationships between children and other adults, the differences between the fantasies of future adult roles and the actual reality of adult life, and the encounter with reality, which enforces a reorganisation of perceptions during the transition from school to work, all lead to this experience being one of shock. An example of this could be that the young person before entering work, has a perception or fantasy that work will be a positive experience and will have no negative effect on them. In such a fantasy the young person does not perceive the reality of adult working life as being one without long school holidays, short working days and extended 'break times'. The reality of work is different from the perceptions of the young person and, for Elias, the realisation that nothing will ever be the same in terms of school holidays or the general loss of the 'freedoms' that accompany childhood lead the young person to experience a 'reality-shock'. Interestingly, Elias suggested that the reality shock was greater for girls as they have had a less 'realistic' upbringing as compared to boys.

In an unpublished memo (Elias 1964b) Elias further clarified his thoughts on shock and suggested that it was possible to classify each 'interview' in terms of a particular 'reality types'. One of the reality types Elias suggested could be the 'types of relationship between expectation and reality'. Elias argued that there were three main possibilities that the young workers would experience. First, that expectations of the job would be more or less like school but the reality was that work was indeed very different. For example, the supervisors at work were not like teachers and, whereas at school it was possible to 'mess about' (or act in ways not approved of by adults) when not directly supervised, at work it was not possible to 'mess about' at all . Second, the expectation that work will be terrible and the reality was that work was not as bad as expected. For example, that work would be hard and the young person would be made to work like slaves, whereas the reality was different with less control of the young person and great possibilities for controlling the pace of work. Finally, the expectation that the freedom from school would be 'marvellous' but the reality of work and adult life were less 'marvellous' than expected. Leaving school would be almost like an escape from the prison-like or controlled realities of education. However, on escaping the young person finds that work is also controlled and provides little opportunity for the individual expression they so desire. 


\section{Conclusions}

This paper began with two main aims - to introduce this largely unknown aspect of Elias's work to a wider audience beyond the few who were aware of the projects existence and, second, to piece together Elias's shock hypotheses from archived materials. It is clear from the above discussion that the Young Worker Project represented a major undertaking by Elias and is the only example of Elias involvement in large-scale publicly funded survey research. It is also clear that by proposing the shock-hypothesis Elias was trying to further elaborate on, and further explore, ideas presented in The Civilising Process and other works. However, based on the discussion there are two final points that we would like to make to conclude this paper. The first of these deals with the shock hypothesis and the second with Elias's legacy in British Sociology.

Although the shock hypothesis builds upon Elias's other work, this hypothesis has found little support within the literature of youth transitions. Even Elias's own research team questioned the hypothesis are argued that there was little evidence of shock to be found in the data. For example, using data from the pilot study Brown et al (1963) suggested that the younger members of the sample had hardly had time to get over the excitement at not having to adhere to the rigid discipline of school and earning money to experience the 'shock' that Elias refers to.

Our examination of the previous work shows it to be an almost universal finding from actual investigations that, at the time of entry to work for young people, the excitement of leaving school and earning a wage over- shadows other feelings, to a large extent. These preliminary attitudes reduce the impact of experiences of work and life as workers, for a time. (Brown et al, 1963: 1).

Likewise, Ashton and Field (1976) also argued that most young people did not experience severe problems of adjustment during the transition from school to work. They suggest that the view that young people experience shock due to the fact they are isolated from work in educational establishments and suddenly released into work is erroneous and at best common sense. They argue that previous experiences at home, school and amongst their peer groups actually prepares them well to fit in or adjust to the demands of starting work (Ashton and Field 1976: 12). There are other criticisms of the shock hypothesis that can also be used to question legitimacy of this approach. For example, the actual origins of Elias's concern with the problems of adjustment and the adjustment as shock remain unclear and the lack of knowledge of work highlighted by Elias as being significant, may actually more accurately reflect 
the experience of middle class youth as opposed to working class youth. Likewise the data also indicates that many of the young workers had actually worked before they had left school and had some understanding of what work entailed. However, despite these criticisms, a reanalysis of the data emerging from the Young Worker Project does provide some empirical evidence for Elias's shock hypothesis as the following quotations from the interviewer notes reveal

Respondent was the first case I have met of a real traumatic shock on entering work. Her mother said that in her first job which only lasted a week she cried every night, couldn't eat her food and couldn't sleep. She wasn't shown how to do anything, the people were snobbish, and she found it generally too much for her. It was quite different at her second job, where, although she had criticism, she seemed to identify strongly with her office group. (D278)

I think this R could qualify as one of Dr. Elias' "Youth islanders", for she seems to live in a two-thirds dream world. This consists of black leather coats, coffee bars, Art and Tech etc. She obviously yearns to be one of the college set and was proud of her affiliations to it...Her ambitions - modelling, air hostess, own salon by 20 are all very out of track with reality. Perhaps her maturity has been put off partly as a result of being an only child of rather old parents. (B605)

An interesting character who seemed to typify Norbert Elias's "Culture Shock". This is to some extent and whose job choices seemed to be rather haphazardly and irrationally chose. Obviously a boy who disliked hard work and enjoyed the more than occasional skive. (A620)

It is also the case that authors are beginning to explore some of the themes that Elias alluded to in his writings on the shock hypothesis. For example, Lawy and Bloomer (2003) reflect on the superficial understanding that the young people in their study had of their own futures and the fact that the future occupational opportunities anticipated by the young people were not forthcoming. The difference between their perceived future opportunities (fantasy) and their actual experiences (reality) have consequences for the young people's identify formation and transformation. Likewise, Elias's concern for understanding the problems that young people experience in their adjustments in leaving school, becoming workers, entering unfamiliar situations for which they are unprepared, earning money, changing family relations, and working with others beyond the close circle of school friends, has some overlap with the risk, uncertainty, insecurity and individualization debates which are so characteristic of the current literature on youth transitions.

Our second conclusion relates to Elias's standing amongst British sociologists and, although speculative, is perhaps worthy of consideration. The significant role that Norbert Elias has played in the sociology department at the University of Leicester has been highlighted by many (Kilminster 1987; Mennell 1992; Van Krieken 1998; 
Dunning 2002; Halsey 2004; Platt 2004) and it is clear that Elias has been an important influence on the careers of many who went through the Leicester department in the 1950s and 1960s (Halsey 2004). However, despite his apparently central role, many have also questioned why Elias's ideas have not been well received amongst many British sociologists until fairly recently (Kilminster 1987; Mennell 1992; Van Krieken 1998; Dunning 2002). It has been suggested that Elias's previously patchy impact on British sociology may have been due to the lack of English translations, the dominance of Parsons in 1950s and 1960s sociology, his use of psychoanalysis, the increased specialisation amongst sociologists or even just a general lack of awareness (Kilminster 1987; Mennell 1992). Whilst all of the points may be true the Young Worker Project may provide an additional explanation. It is not inconceivable that the way Elias developed, managed and implemented this project may have had a negative effective on the reception of Elias in British sociology. We suggest this as many of the researchers originally involved in the Young Worker Project went on to occupy senior roles within British sociology as professors, heads of departments or held senior positions within the British Sociological Association (see Platt 2003). Regardless of the rights and wrongs of the arguments that took place between Elias and the research team, the researchers felt aggrieved and some still reflect on their experiences with some bitterness and regret. Such experiences and feelings must have impacted on their presentation of Elias to their colleagues within British sociology. As Neustadt (1964b) alleges in a letter to Elias

The research officers... also created difficult and unpleasant situations here by agitating in a most unpleasant and vengeful manner with all sorts of people in the University here and in various other places in the country. (Neustadt 1964b: 1)

The difficulties that have surrounded this project, and the sensitivities which still exist for some of the original research team, have meant this project remained 'lost' for many years. However, it is documented in Elias's own correspondence, and within the interview with Jennifer Platt he clearly felt regret for what had happened during this research and that the project could not be saved. In a later letter to Jennifer Platt, Elias suggested 'the fact that a questionnaire designed and interviews conducted under the influence of divergent views cannot be salvaged by a later effort, was for 
me a lesson which I shall not forget' (Elias, 1972a: 1-2). Such sentiments suggest that a fuller consideration of this aspect of Elias's work is clearly merited and the reanalysis of the data we have recovered more than worthwhile ${ }^{[5]}$.

\section{Acknowledgements}

This emerges from an ESRC project 'From Young Workers To Older Workers: Reflections on Work in the Life Course' (R000223653). The authors were fortunate to visit the Deutsches Literaturarchiv with the aid of a grant from the University of Leicester Research Fund (Grant number FS14002). We would like to express our sincere thanks to the Norbert Elias Foundation for granting us permission to quote some of the archive material presented in this paper. We also grateful to Jason Hughes, Stephen Mennell, Eric Dunning, Joop Goudsblom, Ton Zwaan and Norman Gabriel for their constructive comments on earlier versions of this paper.

\section{Notes}

[1] The Research Officers were Teresa Keil (1962-1964) and David Riddell (19621964). They were supported by a research assistant, Colin Tipton (1962-1963) and Bryan Green (1963-1964).

[2] In the mid 1990s Sheila Allen, Richard Brown and Teresa Keil were asked to write a chapter for a book on their experiences of working with Norbert Elias, however this remains unpublished.

[3] One of the communication problems was that Elias would often write to Ilya Neustadt rather than the research team. Neustadt would then have to interpret and represent Elias's wishes at the committee meetings.

[4] It is interesting to note that for the Realities of Social Research book Platt interviewed Elias and other members of the Young Worker Project team. However, where the Young Worker Project is discussed in the book it is the experiences and accounts of the other researchers, rather than Elias's views, that appear to have informed Platt's analysis.

[5] Data the from the Adjustment of Young Workers to Work Situations and Adult Roles project has been used for the first time as part of a new and wider project 'From Young Workers To Older Workers: Reflections on Work in the Life Course' (ESRC R000223653). The overall aim of the project was to examine the process of adjustment to working life and retirement of a single cohort of male and female workers over the four decades 1962/3-2002/3. This project will analyse the data from the original project and then we aim to trace two hundred of the 854 original young workers for re-interview.

\section{References}

Ashton, D.N. and Field, D. (1976) Young Workers: From School to Work. Hutchinson: London. 
Ashton. D.N. (1974) Careers and Commitment: The Movement from School to Work. In Field, D. (ed) (1974) Social Psychology for Sociologists. London: Nelson.

Ashton, D.N. (1973) The Transition from School to Work: Notes on the Development of Different Frames of Reference Among Young Male Workers. The Sociological Review, Vol.21, pp. 101-125.

Brown, R. (1987) Norbert Elias in Leicester: Some Recollections. Theory, Culture and Society, Vol. 4, pp $533-539$.

Brown, R., Keil, T., and Riddell, D.S.R. (1963) Young Worker Project: Composition of Sample. Unpublished Memorandum, University of Leicester. Marbach: Deutsches Literaturarchiv.

Cherns, A.B. (1965) Unpublished Letter to Norbert Elias, 12 November 1965. Marbach: Deutsches Literaturarchiv.

Dunning, E. (1981) The Figurational Analysis of the Development of Rugby Football: A Reply to Rudd Stokvis. Amsterdam Sociologisch Tijdschrift, Vol. 7, No.4 pp.533-45.

Elias, N. (2000) The Civilising Process. Blackwell: London.

Elias, N. (1998) On Civilization, Power and Knowledge. University of Chicago Press: Chicago.

Elias, N. (1994) Reflections on a Life. London: Polity.

Elias, N. (1980) The Civilising of Parents, in Goudsblom, J. and Mennell, S. (eds) (1998) The Norbert Elias Reader. London: Blackwell.

Elias, N. (1972a) Unpublished Letter to Jennifer Platt, 4 March 1972. Marbach: Deutsches Literaturarchiv.

Elias, N. (1970) What is Sociology. Columbia University Press: New York.

Elias, N. (1964a) Unpublished Letter to Teresa Keil and David Riddell, 4 June 1964. Marbach: Deutsches Literaturarchiv.

Elias, N. (1964b) A Note on the Problem of Typing the Questionnaires, Unpublished, 21 October 1964. Marbach: Deutsches Literaturarchiv.

Elias, N. (1963) Young Worker Project. Unpublished Letter to Illya Neustadt, 24 February 1963. Marbach: Deutsches Literaturarchiv.

Elias, N. (1962) Unpublished Memo: Notes In Reply To The Staff Notes From 16 October 1962, With A Few Additional Remarks On RB's Memorandum To The Problem Of Sampling, 22 October 1962. University of Ghana. (Teresa Keil Collection).

Elias, N. (1962a) Second Memorandum, Unpublished. Marbach: Deutsches Literaturarchiv.

Elias, N. (1962b) Third Memorandum, Unpublished. Marbach: Deutsches Literaturarchiv.

Elias, N. (1961) Application for a Grant for Special Research to DSIR. Unpublished, University of Leicester. (Teresa Keil Collection).

Fletcher, J. (1997) Violence and Civilisation: An Introduction to the Work of Norbert Elias. Cambridge: Polity Press

Goudsblom, J. and Mennell, S. (eds) (1998) The Norbert Elias Reader. London: Blackwell.

Halsey, A.H. (2004) A History of Sociology in Britain. Oxford: Oxford University Press

Hughes, J. (1998) 'Norbert Elias and Process Sociology', in Stones, R. (ed.) Key Sociological Thinkers, London: Macmillan.

Hughes, J. (1997) From Panacea to Pandemic: Towards a Process Sociology of Tobacco-Use in the West. Unpublished PhD thesis. University of Leicester. 
Keil, E.T. (1964) Unpublished Letter to Norbert Elias, 26 June 1964. Marbach: Deutsches Literaturarchiv.

Keil, E.T. and Riddell, D.S. (1964) Unpublished Letter to Norbert Elias, 22 May 1964. Marbach: Deutsches Literaturarchiv.

Keil, E.T., Riddell, D.S. and Tipton C.B. (1963a) Unpublished Letter to Norbert Elias, 1 March 1963. Marbach: Deutsches Literaturarchiv.

Keil, E.T., Riddell, D.S. and Tipton C.B. (1963b) A Research Note: The Entry of School Leavers into Employment, British Journal of Industrial Relations, Vol. 1, No. 3, pp 408-411.

Kilminster, R. (1987) Introduction to Elias. Theory, Culture and Society, Vol. 4, pp 213-22.

Korte, H. (2001) Perspectives on a Long Life: Norbert Elias and the Process of Civilization, in Salumets, T.(ed) (2001) Norbert Elias and Human Interdependencies. McGill-Queen's University Press: Montreal.

Lawy, R., and Bloomer, M. (2003) Identity and Learning as a Lifelong Project: Situating Vocational Education and Work. International Journal of Lifelong Education, Vol. 22, No. 1 pp24-42.

Mennell, S. and Goudsblom, J. (1998) Introduction, in Elias, N. (1998) On Civilization, Power and Knowledge. University of Chicago Press: Chicago.

Mennell, S. (1992) Norbert Elias: An Introduction. London: Blackwell

Neustadt, I. (1964a) Unpublished Letter to Norbert Elias, 8 June 1964. Marbach: Deutsches Literaturarchiv.

Neustadt, I. (1964b) Unpublished Letter to Norbert Elias, 20 July 1964. Marbach: Deutsches Literaturarchiv.

Neustadt, I. (1962) Unpublished Letter to Norbert Elias, 22 October 1962. Marbach: Deutsches Literaturarchiv.

Platt, J. (2004) Epilogue Essay: Jennifer Platt. In Halsey, A.H. (2004) A History of Sociology in Britain. Oxford: Oxford University Press.

Platt, J. (2003) The British Sociological Association: A Sociological History. Durham: Sociology Press.

Platt, J. (1976) Realities of Social Research. London. Catto Windus

Riddell, D.S. and Keil, E.T (1963) Young Worker Project: Note on Sample, Unpublished. University of Leicester. (Teresa Keil Collection).

Smith, D. (2000) Norbert Elias and Modern Social Theory. London: Sage.

Szakolczai, A. (2000) Norbert Elias and Franz Borkenau: Intertwinded Life-Works. Theory, Culture and Society, Vol. 17, No.2 -45-69.

Tabboni, S. (2001) The Idea of Time in Norbert Elias. Time and Society, Vol. 10, No. , pp 5-27.

Van Krieken, R. (1999) The Barbarism of Civilisation: Cultural Genocide and the Stolen Generations. British Journal of Sociology, Vol.50, No. 2 pp 297-315.

Van Krieken, R. (1998) Norbert Elias. London: Routledge

Van Krieken, R. (1989) Violence, Self-Discipline and Morality: Beyond the Civilizing Process. Sociological Review, Vol. 37, no.2 pp 193-218.

Young Worker Project (1962a) Minutes of Second Meeting 7 March 1962, Unpublished. University of Leicester.

Young Worker Project (1962b) Minutes of Fifth Meeting 18 April 1962, Unpublished. University of Leicester.

Young Worker Project (1962c) Minutes of Sixth Meeting 9 May 1962, Unpublished. Marbach: Deutsches Literaturarchiv. 
